\title{
Emergence of Secondary Acute Leukemia in a Patient Treated for Osteosarcoma: Implications of Germline TP53 Mutations
}

Carlos Panizo, MD, ${ }^{1}$ Ana Patiño, $\mathrm{PhD},{ }^{2} \mathrm{M}^{\mathrm{a}}$ José Calasanz, $\mathrm{PhD},{ }^{3}$ José Rifón, MD, ${ }^{1}$ Luis Sierrasesumaga, $\mathrm{MD},{ }^{2}$ and Eduardo Rocha, $\mathrm{MD}^{1 *}$

${ }^{1}$ Department of Hematology, University Clinic of Navarra, School of Medicine, University of Navarra, Pamplona, Spain.

${ }^{2}$ Department of Pediatrics, University Clinic of Navarra, School of Medicine, University of Navarra, Pamplona, Spain.

${ }^{3}$ Department of Genetics, University Clinic of Navarra, School of Medicine, University of Navarra, Pamplona, Spain.

*Correspondence to: Eduardo Rocha, Department of Hematology, University Clinic, Pamplona 31008, Spain. E-mail: erocha@cun.unav.es

\section{Background}

Secondary leukemia and myelodysplastic syndromes have been reported in patients following treatment for a wide range of neoplastic disorders. However, second malignancies after chemotherapy and/or irradiation for osteosarcoma are unusual.

\section{Procedure}

We report the case of a 15-year-old girl who developed a myelodysplastic syndrome with evolution to acute nonlymphocytic leukemia after treatment for osteosarcoma. Therapy-related acute leukemia karyotype findings such as abnormalities of chromosomes 5, 7, and 17 were found in the cytogenetic analysis. Moreover, using denaturing gradient gel electrophoresis and DNA sequencing, we detected the presence of a double germline mutation in exon 7 of the TP53 gene.

\section{Conclusion}

This observation supports the possibility of a causal relationship between germline TP53 mutations and the development of secondary leukemia and myelodysplasia.

\section{Key words}

Osteosarcoma; acute nonlymphocytic leukemia; TP53 gene 


\section{INTRODUCTION}

Among children diagnosed with cancer nowadays, 70\% will be long-term survivors. This fact makes secondary malignant neoplasms the most serious complication of cancer therapy [1]. In past years, several groups have reported acute leukemia in children as a complication of chemotherapy and radiation regimens [2,3]. However, the development of leukemia after treatment for osteosarcoma has rarely been recorded $[4,5]$.

Although exposure to DNA damaging agents can contribute to the emergence of neoplastic disease, identification of tumor genetic changes through cytogenetic and molecular procedures suggests a genetic component in the development of human cancer. The TP53 gene, located on the short arm of chromosome 17, is a tumor suppressor gene whose product plays a key role in neo-plastic transformation [6]. TP53 gene mutations are generally missense changes involving almost exclusively exons 4 through 8 [7]. These mutations, either de novo or inherited, result in a protein with increased stability and prolonged half-life that can lead to cellular transformation. An increased incidence of TP53 gene aberrations and abnormalities of chromosome 17 has been reported in children and young adults with second malignant neoplasms [8]. We describe a case of acute nonlymphocytic leukemia preceded by a myelodysplastic phase after chemo- and radiotherapy administration to a TP53 double mutation carrier girl with chondroblastic osteosarcoma.

\section{CASE REPORT}

A 15-year-old girl was diagnosed with nonmetastatic chrondroblastic osteosarcoma of the middle third of the right femur in February 1989. No family history of cancer was reported. She received neoadjuvant chemotherapy with 3 courses of methotrexate 12 $\mathrm{g} / \mathrm{m}^{2}$, vincristine $1.75 \mathrm{mg} / \mathrm{m}^{2}$ and doxorubicin $90 \mathrm{mg} / \mathrm{m}^{2}$. Simultaneously, she was treated with 3 cycles of intra-arterial carboplatin at $150 \mathrm{mg} / \mathrm{m}^{2} \times 3$ days administered at 3 week intervals. A limb salvage procedure with tumor resection and a functional reconstruction using bone graft was performed in April 1989. Histopathologic studies of the resected specimen demonstrated less than 20\% tumor necrosis. Both intra- and postoperative radiotherapy of the tumor bed and surrounding tissues were performed at total doses of $20 \mathrm{~Gy}$ and $46 \mathrm{~Gy}$ respectively. Chemotherapy administered during the postoperative period included 6 courses of methotrexate $10 \mathrm{~g} / \mathrm{m}^{2} /$ week every fourth week, and 7 courses of doxorubicin $50 \mathrm{mg} / \mathrm{m}^{2}$, carboplatin $100 \mathrm{mg} / \mathrm{m}^{2}$ and cisplatin 40 $\mathrm{mg} / \mathrm{m}^{2}$. During this time, the patient also received a cycle with ifosfamide $4,5 \mathrm{~g} / \mathrm{m}^{2}$, dactinomycin $1,8 \mathrm{mg} / \mathrm{m}^{2}$ and bleomycin $30 \mathrm{mg} / \mathrm{m}^{2}$. Total duration of therapy was 10 months. The patient remained well until October 1992 when local recurrence in the right proximal femur was documented and limb amputation was performed. No further treatment was applied until November 1993 when she developed a lung metastasis and a mass on the left femoral condyle that after biopsy was found to be an osteogenic sarcoma. Surgical excision of the lung metastasis and tumor resection of the knee with replacement by a prosthesis were performed. Between December 1993 and October 1994 she received 10 additional courses of chemotherapy with methotrexate at high doses $15 \mathrm{~g} / \mathrm{m}^{2}$, carboplatin $600 \mathrm{mg} / \mathrm{m}^{2}$ and etoposide $400 \mathrm{mg} / \mathrm{m}^{2}$. In March 1995 a new single lung metastasis was resected. Six months later a local recurrence in the soft 
tissues of the left knee and another single lung metastasis were found, both of them requiring surgical treatment. No chemotherapy or radiotherapy were performed after these surgical treatments.

In December 1995 persistent anemia and thrombocytopenia were noted. Blood count showed: hemoglobin, $75 \mathrm{~g} / \mathrm{L}$; leukocytes, 7,3 x 10\%/L, (myelocytes 7\%, metamyelocytes $13 \%$, neutrophils $21 \%$, basophils $1 \%$, lymphocytes $51 \%$, monocytes $4 \%$, blasts 3\%); platelets $23 \times 10^{9} / \mathrm{L}$. Bone marrow aspirate was consistent with refractory anemia with excess blasts, and treatment with low-dose cytarabine was performed during 15 days. A new bone marrow aspirate at the end of treatment showed progression to acute nonlymphocytic leukemia. Complete remission was attained after induction with intensive chemotherapy consisting of idarubicin $10 \mathrm{mg} / \mathrm{m}^{2}$ x 3 days, cytarabine $100 \mathrm{mg} / \mathrm{m}^{2}$ x 10 days and etoposide $100 \mathrm{mg} / \mathrm{m}^{2}$ x 5 days, and consolidation with a cycle of mitoxantrone $12 \mathrm{mg} / \mathrm{m}^{2} \times 3$ days and cytarabine $1 \mathrm{~g} / \mathrm{m}^{2} \times 6$ days. The patient underwent allogeneic peripheral blood progenitor cells transplantation from her HLA-identical sister. The conditioning regimen consisted of busulfan $4 \mathrm{mg} / \mathrm{kg}$ x 4 days and cyclophosphamide $60 \mathrm{mg} / \mathrm{kg}$ x 2 days; cyclosporine A and methotrexate were given as prophylaxis for graft-versus-host disease. Successful engraftment, defined as an absolute neutrophil count greater than $0,5 \times 10^{9} / \mathrm{L}$, was achieved on day +14 . The platelet count was greater than $50 \times 10^{9} / \mathrm{L}$ on day +18 . A bone marrow aspirate performed on day +46 showed no blast cells but she relapsed on day +104 . Acute renal failure developed on day +130 . Her condition deteriorated further and the patient died on day +132 .

\section{MOLECULAR ANALYSIS}

One tissue sample from the lung metastasis resected in March 1995, another from peripheral blood lymphocytes at that time, and another one from bone marrow at diagnosis of acute leukemia were obtained to perform the molecular analyses. Genomic DNA was obtained by isolation and purification with proteinase $\mathrm{K}$ and extraction using conventional phenolchloroform procedures both in the case of peripheral lymphocytes, fresh tumor tissue and bone marrow [9]. Screening for mutations at exons 5 through 8 of the TP53 gene was performed as previously described [10,11]. In brief, $300 \mathrm{ng}$ of genomic DNA were amplified in a $50 \mu \mathrm{l}$ PCR reaction (polymerase chain reaction) containing 20 pmol of each primer, $200 \mu \mathrm{M}$ dNTPs, $20 \mathrm{mM}$ Tris-HCl (pH 8.5), $16 \mathrm{mM}$ $\left(\mathrm{NH}_{4}\right)_{2} \mathrm{SO}_{4}, 2.5 \mathrm{mM} \mathrm{MgCl} 2,150 \mu, \mathrm{g} / \mathrm{ml} \mathrm{BSA}$, and 1,5 units of Taq DNA polymerase (BioTaq, Bioprobe Systems). DNA samples were analyzed by denaturing gradient gel electrophoresis (DGGE) [12]. Samples were loaded onto $12 \%$ or $6,5 \%$ polyacrylamide gels (acrylamide:bisacrylamide 37,5:1) containing the appropriate denaturant gradient (100\% denaturant corresponds to $7 \mathrm{M}$ urea and 40\% deionized formamide). Sequences of primers, PCR conditions, gradient concentrations and running conditions for each TP53 exon were those described by Børresen and coworkers for exons 5, 7 and 8 and by Hamelin and coworkers for exon $6[10,11]$. Bands with altered electrophoretic mobilities corresponding to TP53 exon 7 were cycle sequenced using the Thermo Sequenase Cycle Sequencing kit (Amersham Life Science).

The sequencing of the DNA extracted from the metastasis, the peripheral blood lymphocytes and the bone marrow blasts carried a double mutation (Figure 1): one of 
the alleles (allele 1) had a frameshift mutation originated by the deletion of a cytosine, and the other one (allele 2) a missense tandem mutation CC to TT that changed the wild type proline into a phenylalanine in the codon 250 of the protein.

\section{CYTOGENETIC STUDIES}

Cytogenetic studies were performed on bone marrow cells using 24-hour cultures and G-banding. A minimum of 30 well-spread metaphases were analysed from each case. Karyotypes were described according to the International System for Human Cytogenetic Nomenclature (ISCN) [13].

Cytogenetic analysis of bone marrow obtained at the time of diagnosis of myelodysplastic syndrome showed normal metaphases in 1 of 35 (3\%) and four abnormal clones 43,XX,t(3;6) (q21;p21),-5,-17,-18 (17\% metaphases); 43,XX,t(3;6) (q21;p21),-5,-17,-18,del(22)(q11) (25\% metaphases); 45,XX,t(3;6)(q21;p21),del(5) (q13q32),-7,-17,-18,+del(22)(q11),+mar(50\%metaphases);85-90,XXX,t(3;6) (q21;p21), inc (7\% metaphases). A partial karyotype illustrating the $t(3 ; 6)$ is shown in Figure 2. A new cytogenetic study was performed after the treatment with low-dose cytarabine, at diagnosis of nonlymphocytic leukemia. Besides previous findings, a new clone was detected: 43,XX, t(3;6) (q21;p21), -5, der(7)t(7;?)(q34;?),-17,-18,del(22)(q11) (2\% metaphases).

After induction and consolidation therapy both morphologic and cytogenetic remissions were achieved. A normal female karyotype was shown in all 52 metaphases analyzed. A new cytogenetic study was performed after the allogeneic peripheral blood progenitor cell transplantation. No abnormal clones were detected. When relapse was observed, the cytogenetic analysis showed normal metaphases in 24 of 37 (65\%) and two abnormal hypodiploid clones. 43,XX,t(3;6)(q21;p21),-5, -17,-18 (27\% metaphases); 45,XX,t(3;6) (q21;p21), $\operatorname{del}(5)(q 13 q 32), \operatorname{der}(7) t(7 ; ?)$ (q34;?),-7,-17,-18,+del(22) (q11),+mar (8\% metaphases).

\section{DISCUSSION}

TP53 is a tumor suppressor gene located on the short arm of human chromosome 17 that encodes a nuclear phosphoprotein that functions as a negative regulator of cell proliferation. Mutations in this gene have been associated with many human tumours including osteosarcomas. The development of osteosarcoma is a result of the loss of normal p53, which then releases bone cells from p53 suppression of neoplastic growth $[14,15]$. Mutation of TP53, followed by a loss of the remaining wild type allele, usually by deletion, may inactivate that gene and determine the emergence of cell transformation. In our patient, the mutations were present both in the tumour as well as in the germline, but samples from her parents were not available, so that we cannot be sure of the real significance and possible inheritance of the mutations. The presence of two TP53 mutated alleles has as a consequence the absence of wild type p53 protein. Given the key role of the p53 protein in the cell cycle progression and the suppression of abnormal cell growth, we are able to better understand the malignant behaviour of the 
osteosarcoma and its aggressive progression in our patient [16]. Although these mutations have already been described in the literature, they have never been reported, to our knowledge, in the same patient [17].

Therapy-related second malignancies have been identified in patients receiving radiotherapy, prolonged chemotherapy regimes or combined modality therapy for a variety of primary neoplasms. With the advances in treatment of childhood cancer, more children are surviving for longer periods of time and the possibility of developing a second malignancy has become an important concern [18]. Although second malignancies following therapy for osteosarcoma are unusual, its treatment has been related to development of breast cancer, esophageal carcinoma and soft tissue sarcoma $[1,19,20]$. An increased incidence of TP53 mutations has been recently reported in children diagnosed with osteosarcoma and second cancers [8].

Secondary leukemia represents $20 \%$ of all second neoplasms following chemotherapy and has been reported in patients treated for a wide range of primary malignant tumours [21]. However, it is rarely observed in patients with osteosarcoma [4,5,22-28]. The main risk factor in the development of secondary leukemia seems to be treatment with alkylating agents, cisplatin and epipodo-phyllotoxins whose cytotoxic activity is induced by a p53-dependent apoptotic cell death program [29-31]. Although radiotherapy could be a factor in the development of subsequent leukemia, there is no evidence that such radiotherapy to the involved field contributes to the emergence of this type of leukemia [25,29]. A genetic component expressed as host susceptibility could enhance the effect of all these risk factors. Decreased cell death caused by exposure to DNA-damaging chemo-therapy and irradiation could be the way in which TP53 mutations contribute to leukemogenesis [32]. The case we report here occurred following treatment with several drugs, including high cumulative amounts of carboplatin, cisplatin and etoposide, and small amounts of alkylating agents, such as ifosfamide. As this patient had been exposed to multiple chemotherapy agents, it is difficult to assign the cause of the secondary leukemia to a specific drug. The addition of radiotherapy to the involved area probably did not contribute to the myelodysplastic syndrome in this patient, although an effect for the combination cannot be ruled out. It is also possible that secondary effects of previous treatment together with the presence of TP53 germline mutations may contribute to the development of myelodysplasia.

Hypodiploidy and abnormalities of chromosomes 3, 5, 7 and 17 are associated with secondary leukemias [33- 36]. The 11q23 abnormality has also been reported, and is often associated with the appearance of epipodophyl-lotoxin-related leukemias [31]. Cytogenetic abnormalities occurring in our patient were analogous to those found in patients with leukemia that follows the use of alkylating agents [4,24,29]. Molecular analysis of bone marrow blasts performed in our patient, and the presence of cytogenetic abnormalities of chromosome 17 suggest that TP53 mutations could play an important role in the development of leukemia. Recent investigations have demonstrated that TP53 gene is important in maintaining genomic integrity [37]. The accumulation of cytogenetic abnormalities in the myelodysplastic marrow cells of our patient could reflect the high mutation rate that results when there is an absence or a functional alteration of wild-type TP53 as the cellular sensor of damaged DNA.

Clinically, secondary leukemias have several features: a latency period of 3 to 6 years after treatment, a preleukemic presentation as myelodysplastic syndrome and a poor 
response to conventional chemotherapy [33]. A low remission rate and a very poor survival are observed among patients with secondary leukemia [33,34]. Some features have been associated with shorter survival: karyotypic abnormalities other than balanced translocations or inversion of chromosome 16, age of 65 or older and marrow blasts 5\% or more [33]. TP53 mutations have become a strong prognostic factor in secondary leukemias because these mutations have been recently implicated as one of the causes of resistance to chemotherapy [38]. Our patient had an ominous prognosis, but complete remission was achieved with intensive chemotherapy. Ultimately, the patient died, despite the fact that an allogeneic peripheral blood progenitor cell transplantation was performed.

In conclusion, we report the case of an acute leukemia preceded by a myelodysplastic phase after treatment for chondroblastic osteosarcoma. Cytogenetic and molecular studies performed on different tissues showed that tumoural development could be related, in this patient, with TP53 mutations. This observation supports the proposal by some authors that children with osteosarcoma should be considered for predictive testing for TP53 mutations [8].

\section{REFERENCES}

1. Meadows AT, Baum E, Fossati-Bellani F, et al.: Second malignant neoplasms in children: An update from the Late Effects Study Group. J Clin Oncol 3:532-538, 1985.

2. Pui CH, Hancock ML, Raimondi SC, et al.: Myeloid neoplasia in children treated for solid tumors. Lancet 336:417-421, 1990.

3. Kaplinsky C, Frisch A, Cohen IJ, et al.: T-cell acute lymphoblastic leukemia following therapy for osteosarcoma. Med Pediatr Oncol 20:229-231, 1992.

4. Jeha S, Jaffe N, Robertson R: Secondary acute non-lymphoblastic leukemia in two children following treatment with a cisdiamminedichloroplatinum-II-based regimen for osteosarcoma. Med Pediatr Oncol 20:71-74, 1992.

5. Pappo A, Schneider NR, Sanders JM, et al.: Secondary myelodysplastic syndrome complicating therapy for osteogenic sarcoma. Cancer 68:1373-1375, 1991.

6. Harris CC, Hollstein M: Clinical implications of the p53 tumor-suppressor gene. N Engl J Med 329:1318-1327, 1993.

7. Fenaux P, Jonveaux P, Quiquandon I, et al.: P53 gene mutations in acute myeloid leukemia with 17p monosomy. Blood 78:1652-1657, 1991.

8. McIntyre JF, Smith-Sorensen B, Friend SH, et al.: Germline mutations of the p53 tumor suppressor gene in children with osteosarcoma. J Clin Oncol 12:925930, 1994.

9. Sambrook J, Fritsch EF, Maniatis T: “Molecular cloning: a laboratory manual”. New York: Cold Spring Harbor Laboratory, Cold Spring Harbor, N.Y., 1989.

10. Børresen AL, Hovig E, Smith-Sørensen B, et al.: Constant denaturant gel electrophoresis as a rapid screening technique for p53 mutations. Proc Natl Acad Sci USA 88:8405-8409, 1991.

11. Hamelin R, Jego N, Laurent-Puig P, et al.: Efficient screening of p53 mutations by denaturing gradient gel electrophoresis in colorectal tumors. Oncogene 8:2213-2220, 1993. 
12. Fischer SG, Lerman LS: DNA fragments differing by single base-pair substitutions are separated in denaturing gradient gels: correspondence with melting theory. Proc Natl Acad Sci USA 80: 1579-1583, 1983.

13. ICSN (1991): Guidelines for Cancer Cytogenetics. Supplement to an International System for Human Cytogenetic Nomenclature. Mitelman F (de). Basel: S Karger.

14. Miller C, Koeffler HP: p53 mutations in human cancer. Leukemia 7(suppl 2):18-21, 1993.

15. Miller CW, Aslo A, Tsay C, et al.: Frequency and structure of p53 rearrangements in human osteosarcoma. Cancer Res 50:7950- 7954, 1990.

16. Levine AJ, Perry ME, Chang A, et al.: The 1993 Walter Hubert Lecture: The role of the p53 tumour suppressor gene in tumori-genesis. Br J Cancer 69:409416, 1994.

17. Hollstein M, Rice K, Greenblatt MS, et al.: Database of p53 gene somatic mutations in human tumors and cell lines. Nucleic Acids Res 22:3551-3355, 1994.

18. Donaldson SS: Lessons from our children. Int J Radiat Oncol Biol Phys 26:739749, 1993.

19. Knowling MA, Basco VE: Breast cancer after treatment for osteosarcoma. Med Pediatr Oncol 14:51-53, 1986.

20. Dewar JM, Courtney JT, Byrne MJ, et al.: Esophageal cancer in a young woman after treatment for osteosarcoma. Med Pediatr Oncol 16:287-289, 1988.

21. Kaldor J: Second cancer following chemotherapy and radio-therapy. An epidemiological perspective. Acta Oncol 29:647-655, 1990.

22. Fenaux P, Jouet JP, Bauters F: Translocation t(9J1)(p21;q23) with acute myelomonocytic leukemia after chemotherapy for osteosarcoma: Good response to antileukemic drugs. J Clin Oncol 5:1304-1305, 1987.

23. Kingston JE, Hawkins MM, Draper GJ, et al.: Patterns of multiple primary tumours in patients treated for cancer during childhood. Br J Cancer 56:331338, 1987.

24. Whang-Peng J, Young RC, Lee EC, et al.: Cytogenetic studies in patients with secondary leukemia/dysmyelopoietic syndrome after different treatment modalities. Blood 71:403-414, 1988.

25. Jacobs AD, Gale RP: Acute myelogenous leukemia following radiation therapy and chemotherapy for osteogenic sarcoma. Cancer Treat Rep 68:909-911, 1984.

26. Sozzi G, Miozzo M, Orazi A, et al.: Cytogenetic study in therapyrelated myelodysplastic syndromes (t-MDS) and acute non-lymphocytic leukemia (tANLL). Br J Cancer 61:425-428, 1990.

27. Davies SV, Murray JA, Bowser-Riley SM: Secondary leukemia with a translocation (8;21)? Cancer Genet Cytogenet 31:271-274, 1988.

28. Kapelushnik J, Dubé L, Wilson P, et al.: Acute lymphoblastic leukemia with $\mathrm{t}(4 \mathrm{~J} 1)$ translocation after osteogenic sarcoma. Cancer 67:2887-2889, 1991.

29. Tucker MA, Meadows AT, Boice JD, et al.: Leukemia after therapy with alkylating agents for childhood cancer. J Natl Cancer Inst 78:459-464, 1987.

30. Lowe SW, Ruley HE, Jacks T, et al.: p53 dependent apoptosis modulates the cytoxicity of anticancer agents. Cell 74:957-967, 1993.

31. Whitlock JA, Greer JP, Lukens JN: Epipodophyllotoxin-related leukemia. Identification of a new subset of secondary leukemia Cancer 68:600-604, 1991.

32. Felix CA, Hosler MR, Provisor D, et al.: The p53 gene in pediatric therapyrelated leukemia and myelodysplasia. Blood 87:4376- 4381, 1996. 
33. Kantarjian HM, Keating MJ, Walters RS, et al.: Therapy-related leukemia and myelodysplastic syndrome: Clinical, cytogenetic and prognostic features. J Clin Oncol 4:1748-1757, 1986.

34. Le Beau MM, Albain KS, Larson RA, et al.: Clinical and cytogenetic correlations in 63 patients with therapy-related myelodysplastic syndromes and acute nonlymphocytic leukemia: Further evidence for characteristic abnormalities of chromosomes no. 5 and 7. J Clin Oncol 4:325-345, 1986.

35. Iurlo A, Mecucci C, Van Orshoven A, et al.: Cytogenetic and clinical investigation in 76 cases with therapy-related leukemia and myelodysplastic syndrome. Cancer Genet Cytogenet 43:227- 241, 1989.

36. Groupe Francaise de Cytogenetique Hematologique: Chromosome analysis of 63 cases of secondary nonlymphoid blood disorders: A comparative study. Cancer Genet Cytogenet 12:95-104, 1984.

37. White AE, Livanos EM, Tlsty TD: Differential disruption of genomic integrity and cell cycle regulation in normal human fibroblasts by the HPV oncoproteins. Gene Dev 8:666-677, 1994.

38. Wattel E, Preudhomme C, Hecquet B, et al.: p53 mutations are associated with resistance to chemotherapy and short survival in hematologic malignancies. Blood 84:3148-3157, 1994. 
A $\quad$ C $\quad$ G $\quad$ T

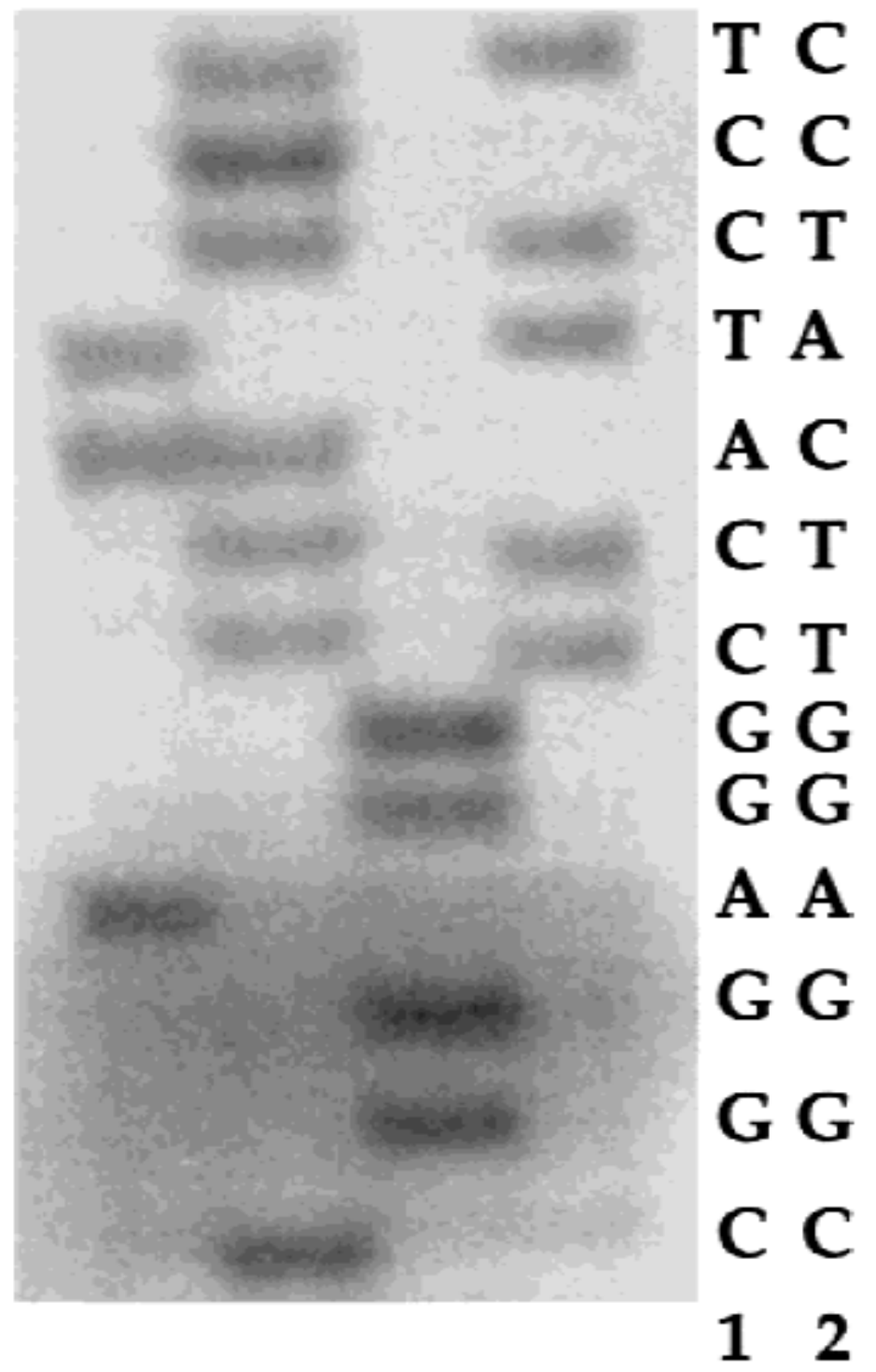

Figure 1. Sequencing showing the complex mutant pattern of TP53 exon 7: one allele (1) presents deletion of a " $C$ "' that causes a shift in the coding frame and the other allele (2) has a tandem transition " $\mathrm{CC}$ ' to " $\mathrm{TT}$ ', that changes the codified amino acid at position 250 . 


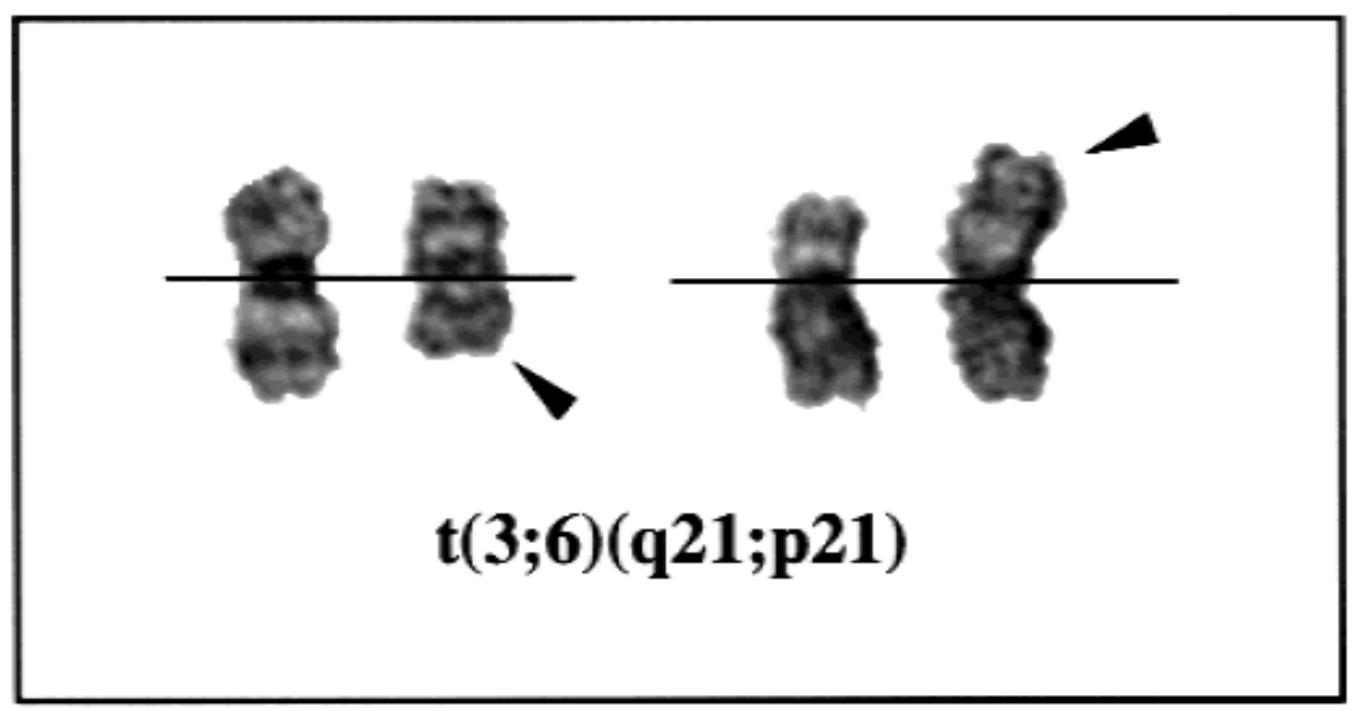

Figure 2. Partial G-banded karyotype showing the translocation $t(3 ; 6)(q 21, p 21)$. Arrows indicate abnormal chromosomes. 